\title{
YURUPARÍ: MÁSCARAS Y PODER ENTRE LOS PIAROAS DEL ORINOCO
}

ALEXANDER MANSUTTI RODRÍGUEZ ${ }^{1}$

$U N E G$

\begin{abstract}
RESUMEN: En el noroccidente amazónico se realizan, entre otras, dos tipos de fiestas: una enmascarada dedicada a la cosecha de Bactris gassipaes y otras frutas, y otra con flautas sagradas dedicada a evocar seres extraordinarios. Ellas, cuando coinciden en un mismo pueblo, se realizan en momentos diferentes. Sin embargo, en el caso de los Piaroas y Wirös de la cuenca del Orinoco, ambas fiestas coinciden entiempo y lugar. En este ensayo vamos a describir los personajes y procedimientos que son parte de la fiesta y a evaluar algunos de los juegos de poder de género y edad que en ella se expresan.

Se trata de una fiesta que consolida alianzas de los shamanes y sus comunidades con los dueños de animales y plantas sometidas a la depredación piaroa, que institucionaliza la expropiación por los hombres y la redefinición hacia lo doméstico del poder femenino, y que transforma una sociedad sin grandes jerarquías en su citianeidad en una sociedad altamente jerarquizada mientras dura la fiesta.
\end{abstract}

PALABRAS CLAVE: Yurupari; piaroas; poder; jerarquía, ritual.

ABSTRACT: In northwest Amazonia, among other kinds, two celebrations occur: one with masks dedicated to the harvest of Bactris gasipaes and other fruits, and another with sacred flutes that evoke extraordinary beings. When both coincide in a same village they occur at different moments. However, to the Piaroa and the Wirö peoples of the Orinoco basin, both ceremonies occur simultaneously at the same place. This paper shall describe participants and procedures of the ceremony and evaluate the gender and age based power game that comes to light during it. This ceremony consolidates alliances between the shamans and their communities with the masters who control animals and plants exploited by the Piaroa people, facilitates men's expropriations and limits women power to the domestic sphere, and shifts a society with no major hierarchical organizations into a highly hierarchical one as long as the ceremony is occuring.

KEYWORDS: Yurupari; Piaroa people; power; hierarchy; ritual.

\footnotetext{
${ }^{1}$ Antropólogo venezolano egresado de la ENAH-Mexico, con maestría en IVIC Venezuela y Doctorado en EHESS en Paris. Actualmente es Coordinador de Investigación y Postgrado de la UNEG en Venezuela. Durante los últimos 30 años ha trabajado con los Piaroa del Orinoco Medio y ha tenido experiencia etnológica con los Pemón y los Kariña. E-mail: pupeto47@ hotmail.com .
}

Espaço Ameríndio, Porto Alegre, v. 6, n. 2, p. 46-75, jul./dez. 2012. 
ALEXANDER MANSUTTI RODRÍGUEZ - Yuruparí: máscaras y poder entre los piaroas...

\section{Introducción}

En este ensayo vamos a describir y analizar un rito de flautas y máscaras realizado por el pueblo indígena Piaroa asentado en la sección media del río Orinoco, aledaña al noroeste amazónico. Analizaremos las relaciones entre ritual y poder en esta vistosa fiesta compleja, es decir en un rito de ritos diferenciados e interrelacionados, practicada por los piaroas y wirös de la Orinoquia, que es conocida como el "Warime", una modalidad de Yuruparí que incluye máscaras sagradas además de los instrumentos musicales de viento, también sagrados.

\section{Las fiestas rituales en el Noroeste amazónico y sus aledaños orinoquenses}

Entenderemos en este ensayo por noroeste amazónico a la región de ríos afluentes al Amazonas que está comprendida entre los ríos Putumayo al sur y el Río Negro al norte. Cuando hablamos de sus aledaños orinoquenses nos referimos a la región comprendida entre los ríos Ventuari-Guaviare al este y sur y el Parguaza-Meta al norte en la cuenca media del Orinoco (ver Figura 1).

Los atributos rituales de esta región se caracterizan, según Oyuela Caicedo (2004), por varios tipos de fiestas de temporada. En este trabajo vamos a analizar dos de ellas que se integran en una sola y compleja llamada Warime: de un lado una fiesta de máscaras asociada a la fecundidad que adquiere múltiples modalidades donde lo único que es universal es que las máscaras representan a seres que coexisten con el hombre y que tienen comportamiento cultural (ARHEM 1998; METRAUX, 1982; REICHEL DOLMATOFF, 1973 y 1978; HUGH JONES, 1979), y una fiesta de flautas sagradas controladas por los hombres iniciados y que está asociada a severas prohibiciones para mujeres y no iniciados (ARHEM, 1981; REICHEL DOLMATOFF, 1973 y 1996; VIDAL, 2000 y 2002; GOLDMAN, 1948 y 1963; GONZÁLEZ ÑANEZ, 1986; HILL, 1986, 1993, 1996 y 2002; C. HUGH JONES, 1979; S. HUGH JONES, 1995; JACKSON, 1983; LOWIE, 1948; MANSUTTI RODRÍGUEZ, $2011 \mathrm{a}, 2011 \mathrm{~b}$ y 2006; METRAUX, 1982; PÉREZ, 1986; WRIGHT, 1998 y 2002; WILBERT, 
ALEXANDER MANSUTTI RODRÍGUEZ - Yuruparí: máscaras y poder entre los piaroas...

1966)2. A esta fiesta se le conoce en la etnografía de tierras bajas como "yuruparí" y ocurre en grupos arawacos, tukanos e independientes del noroccidente amazónico y la Orinoquia.

FIGURA 1: mapa del noroeste amazónico y de su aledaño orinoquense

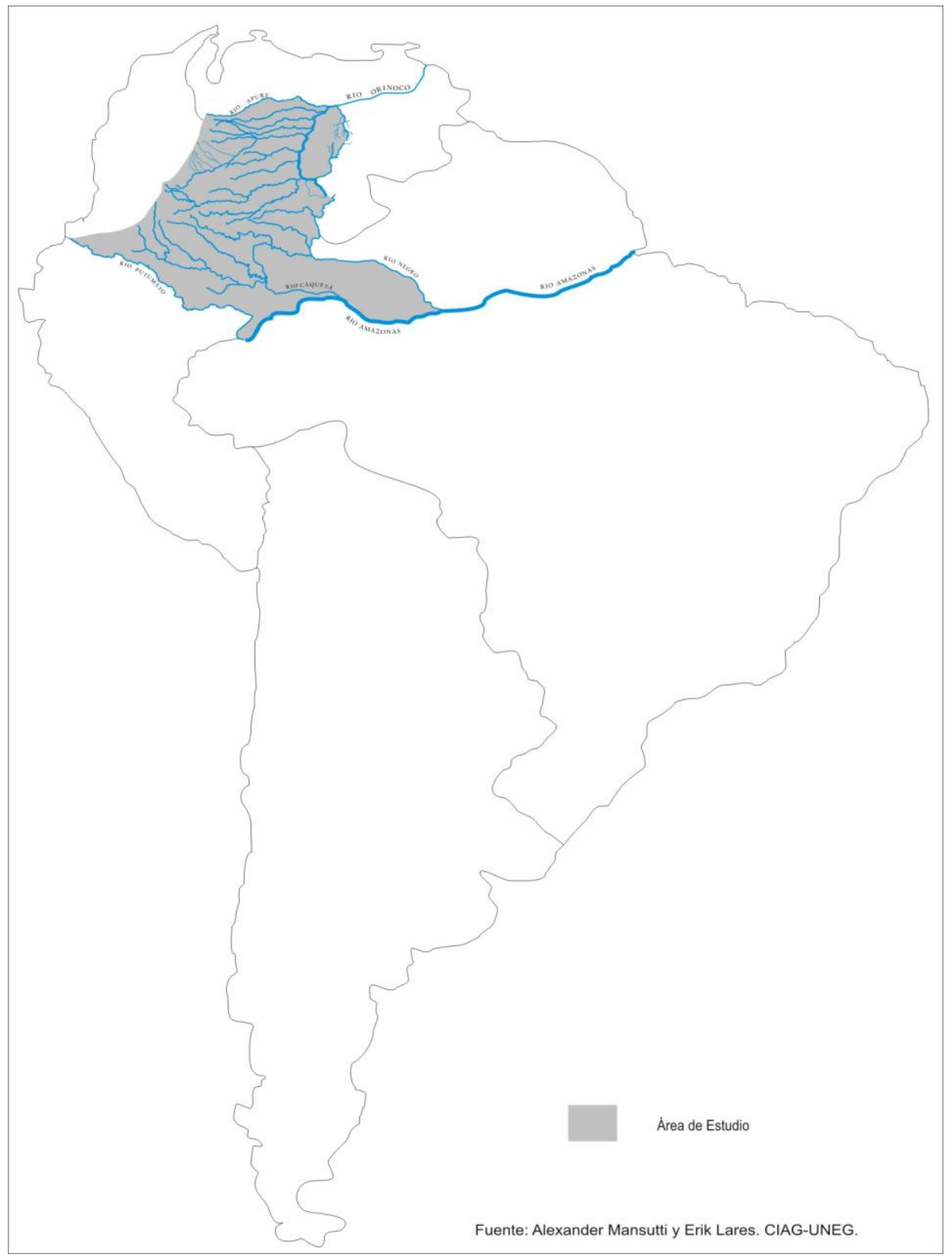

Las fiestas de máscaras, cada una con su propia canción y coreografía de baile, representando con frecuencia a los "dueños de los

\footnotetext{
${ }^{2}$ Chaumeil (1983 y 2011) identifica un yuruparí entre los Yagua pero no lo reportamos por estar en la sección sur del Putumayo, fuera de nuestra área de estudio.
}

Espaço Ameríndio, Porto Alegre, v. 6, n. 2, p. 46-75, jul./dez. 2012. 
ALEXANDER MANSUTTI RODRÍGUEZ - Yuruparí: máscaras y poder entre los piaroas...

animales", estaban presentes en rituales mortuorios cubeo (GOLDMAN, 1963; REICHEL DOLMATOFF, 1978), entre los grupos tukano: letuama, tatimuka, yahuna del Caquetá (OYUELA CAICEDO, 2004), entre los barasana (C. HUGH JONES, 1979) y entre los makuna (ARHEM, 1998; OYUELA CAICEDO, 2004). Por la manera cómo se ejecutan, evocan las fiestas de máscaras reportadas por Goulard (2011) y Oyuela Caicedo (2004) para los tikuna del Putumayo y por Karadimas (2003) para los bora y witoto del mismo río y para los miraña, matapi, andoque, yukuna, y mutuana del Caquetá, todas sociedades ubicadas al sur del Vaupés tukano. En todas estas sociedades, más allá del Vaupés, salvo entre los tikunas, ya no hay yuruparís, sino sólo fiestas de máscaras en la cosecha del pijiguao3. En ellas los participantes pueden llegar a saber quiénes son los portadores de las máscaras. A medida que se va en dirección norte pasamos de la preponderancia de una fiesta de frutas en las cuencas del Putumayo y Caquetá sin restricciones mayores en la identificación de los portadores de las máscaras a la fiesta del yuruparí en el Vaupés, con frecuencia coexistiendo máscaras y flautas pero realizándose en tiempos diferentes, hasta llegar al Orinoco piaroa donde, como veremos, las dos modalidades de fiesta se funden en una y la identidad de los enmascarados adquiere carácter secreto.

El yuruparí es una fiesta, con o sin presencia de máscaras, que se caracteriza por la ejecución de instrumentos de viento, en su mayoría flautas; que se realiza en los ritos de transición masculino (y eventualmente en los femeninos) ${ }^{4}$; en la que los instrumentos que emiten la música están prohibidos a la mirada de las mujeres en edad fértil 5 . Sabemos que se realizan entre los arawaks de la región OrinocoRío Negro: Warekena (GONZALEZ ÑANEZ, 1986; VIDAL, 2002), Wakuenai (HILL, 1986, 1993, 1996, 2002 y 2011 ; JOURNET, 2011 ); entre los Baré (VIDAL, 2002); entre los Baniva (WRIGHT, 1998) y entre los tukanizados

\footnotetext{
${ }^{3}$ Es el fruto de la palmera Bactris gassipaes, un cultígeno que depende de los seres humanos para su dispersión. En marzo ofrece grandes cantidades de frutos que son convertidos en bebidas que son ofrecidas a los enmascarados "dueños de los animales" que asisten a las fiestas (KARADIMAS, 2003 y 2011; OYUELA CAICEDO, 2004).

${ }^{4}$ A quienes quieran profundizar en el tema le recomendamos la lectura de "Warime: La Fiesta. Flautas, trompas y poder en el noroeste amazónico" (MANSUTTI RODRÍGUEZ, 2006) cuyo capítulo final compara los diferentes rituales y el rol que en él cumplen flautas y máscaras.

${ }^{5}$ Por lo general ninguna mujer puede ver los instrumentos musicales del yuruparí. Sólo conocemos de una excepción: Reichel Dolmatoff (1973) informa que, entre los desana las mujeres postmenopaúsicas pueden ver los instrumentos musicales.
} 
Cubeo y Tariana (GOLDMAN, 1963; REICHEL DOLMATOFF, 1996). También entre los tukanos: Desana (REICHEL DOLMATOFF, 1973 y 1996); Bara (JACKSON, 1983); Makuna y Barasana (ARHEM, 1981 y 1998); Uanano y Pirá Tapuya (REICHEL DOLMATOF, 1996); y Tukano (HUGH JONES, 1993; REICHEL DOLMATOF, 1996). Entre los sálivas Piaroas y Wirös (MANSUTTI RODRÍGUEZ, 2006, 2011a y 2011b)); y finalmente entre los independientes Puinavi (WILBERT, 1966); Geral (LOWIE, 1948); y Tukuna (METRAUX, 1982). Se trata de un ritual de flautas presente en todo el noroeste amazónico y cuya presencia empieza a disminuir a medida que vamos hacia el sur desde el Vaupés rumbo al Caquetá y al Putumayo donde las fiestas de máscaras asociadas a la cosecha de Bactris gassipaes alcanzan preponderancia.

Por lo general ambos tipos de fiestas pueden darse en una misma sociedad o en sociedades diferentes pero rara vez se ejecutan juntas y simultáneas. Esa es la particularidad del Warime donde ambos tipos de fiesta, la de máscaras y la de flautas, se integran en una sola.

\section{¿Quiénes son los piaroas?}

El Piaroa es un pueblo indígena de la Orinoquia venezolana famoso por constituir una de las sociedades más pacíficas del mundo (OVERING, 1975 y 1988; OVERING y KAPLAN, 1988; MANSUTTI RODRÍGUEZ, 1991; MONOD, 1987; ANDUZE, 1974). Se ubican en un amplio territorio que va, por el sur, aledaño a la cuenca del Orinoco; por el norte, llegando hasta el Suapure; por el este hasta las cuencas del Guaviarito, Manapiare y Ventuari; y por el oeste hasta las microcuencas del Mataveni y el Zama, en Colombia, hasta llegar a Isla de Ratón, en el curso del Orinoco venezolano, donde toman la vía de la carretera El Burro-Puerto Ayacucho-Samariapo, también en Venezuela (ver Figura 2). Para los piaroas, agredir físicamente, gritar o insultar son indicadores de locura. Un buen piaroa es un asceta que no grita estridentemente ni se ríe a carcajadas y que no come ni tiene sexo en exceso.

Ellos viven en el Orinoco, en las exuberantes selvas tropicales que caracterizan al macizo guayanés. Allí, los piaroas hacen unas hermosas malocas cónico elípticas (ver Figura 3), sin paredes internas que las 
ALEXANDER MANSUTTI RODRÍGUEZ - Yuruparí: máscaras y poder entre los piaroas...

seccionen, que sirve de hogar a una vida colectiva muy tranquila, salvo por los indicios de agresiones shamánicas que les obliga a estar en permanente vigilia6.

Figura 2: Territorio piaroa

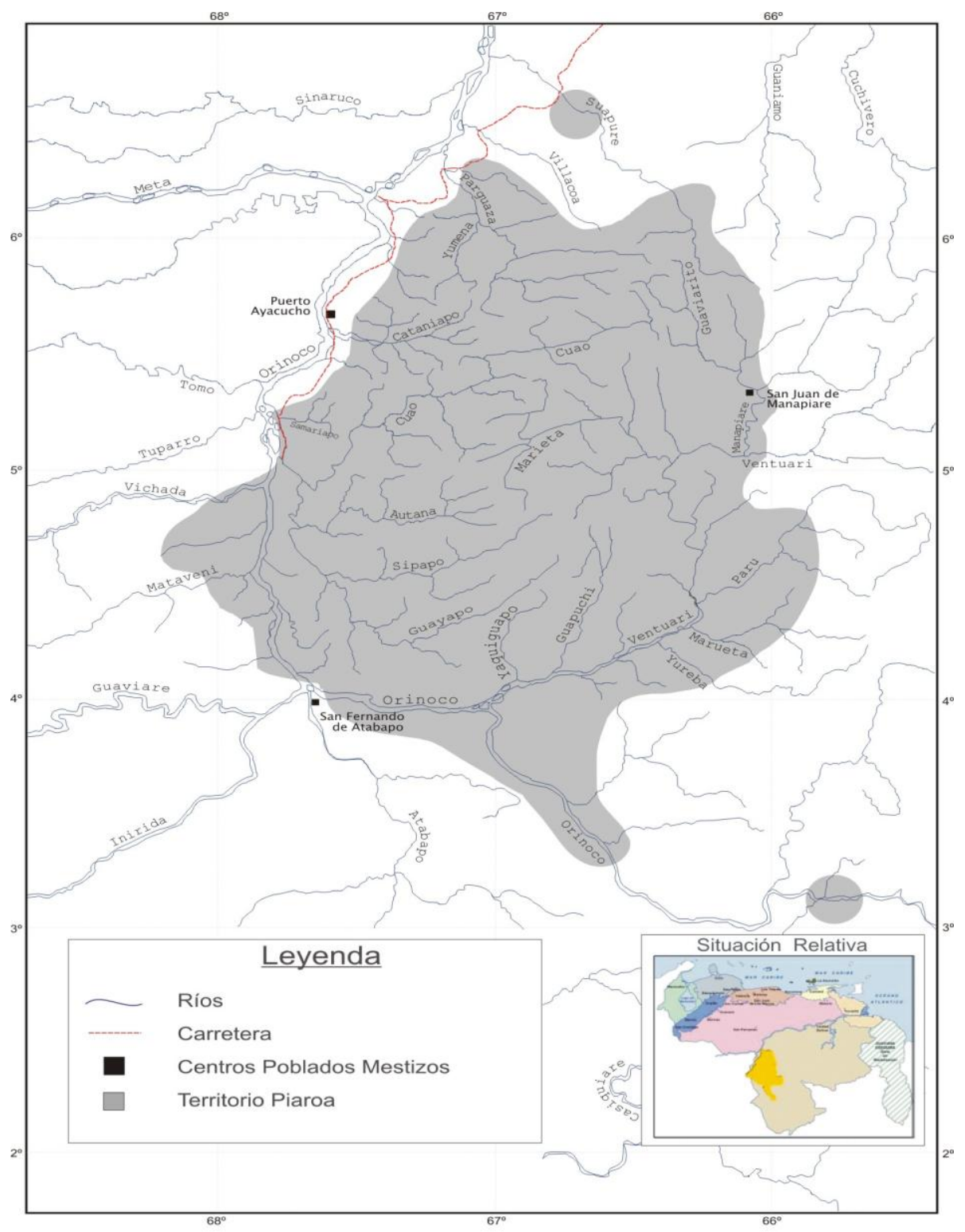

Fuente: Erik Lares. CIAG-UNEG.

La piaroa es una sociedad muy igualitaria durante la mitad del año. Los únicos poderes que se sienten son los asociados a los roles

\footnotetext{
${ }^{6}$ La tranquilidad es una conquista reciente. Hasta el Siglo XIX los piaroas se vieron sometidos a la trata de esclavos y al rapto de sus mujeres, razón por la cual no podemos imaginarnos que el ambiente de tranquilidad que se vive hoy sea equiparable al que se vivía antes.
}

Espaço Ameríndio, Porto Alegre, v. 6, n. 2, p. 46-75, jul./dez. 2012. 
parentales (padres-hijos; suegros y suegras vs yernos y nueras) y a los de los shamanes que aconsejan medidas de precaución y realizan tanto ritos de fecundidad como ritos de agresión para mantener la riqueza y proteger a la comunidad cuya riqueza y salud están bajo su responsabilidad. Las mujeres participan en las discusiones que orientan la gestión cotidiana de la comunidad. No se ven agresiones conyugales ni se escuchan exigencias desaforadas, agresiones retóricas o gritos destemplados.

Figura 3: Foto de maloca piaroa

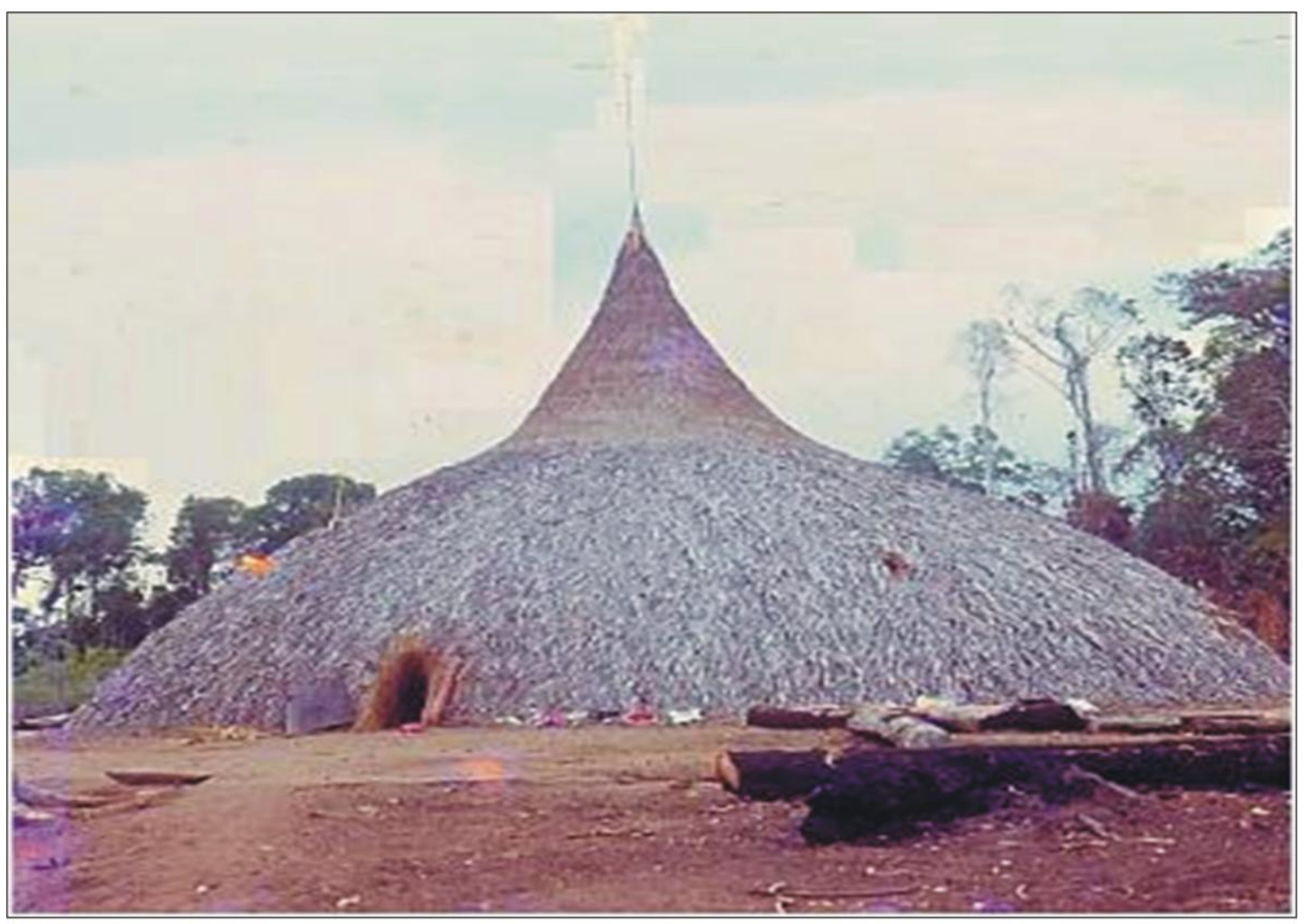

Fuente: Alexander Mansutti. CIAG-UNEG.

Durante la otra mitad del año, cuando los warimes ocurren, las relaciones de género se transforman de manera que el dominio masculino se hace aplastante. La jerarquía masculina se impone hasta que termine la fiesta. No hay violencia física pero si amenazas de su ejercicio; el control sobre las mujeres y los niños es notable. Si van a salir las voces musicales, las mujeres se recogen en la maloca donde se 
encierran tras sus puertas y paredes. La recién construida "Casa de los Hombres" o ruwode deviene espacio prohibido para las mujeres. Las voces musicales se escuchan pero no se ven y los enmascarados entran a la maloca y bailan pero nadie puede asomarse tras la cortina de fibras que recubre su cara. Si alguna transgresión ocurre durante el Warime por la imprudencia de una mujer, toda la comunidad ha de sufrir la pena de muerte sin contemplaciones.

En esta sociedad, el shamanismo ${ }^{7}$ es la única fuerza que genera poderes durables. A medida que las prácticas shamánicas se van haciendo más complejas y peligrosas, niños y mujeres son excluidos. Cuando una persona llega a conocer los cantos más importantes de prevención y cura de enfermedades y de saneamiento de alimentos, ella se convierte en "Dueño de los Rezos" o meyeruwa. El meyeruwa es el maestro del shamanismo creativo. Solo conocemos una mujer meyeruwa. Más compleja aún es la tarea que cumple el "Dueño de los Soplos" o yuwawaruwa. Él es quien maneja los protocolos del shamanismo de agresión o "maripa" en piaroa. Un jefe de comunidad, o itsoderuwa, es necesariamente un meyeruwa poderoso pues a él corresponde mantener fecundo su territorio, pleno de animales y peces. A su lado es conveniente que haya o que él mismo también sea un yuwawaruwa.

Hasta hace dos siglos el piaroa era un grupo montañero seminómada, rodeado de sociedades pacíficas sálivas y de sociedades arawakas; estas últimas se hacían entre si endoguerras altamente ritualizadas (MANSUTTI RODRÍGUEZ, 1990, 1991, 2007 y 2011 c). Con la colonización los arawakos se involucraron en el tráfico de esclavos y algunos de ellos, por ejemplo guaipuinaves y caberres llegaron a liderizar el que surtía las colonias portuguesas, mientras los caribes se convertían, en prósperos comerciantes de esclavos para los enclaves europeos caribeños. Desde ambas redes esclavistas se agredía, sometía y comerciaban piaroas. Es decir, este pueblo que se caracteriza por su aversión a la violencia física, estaba rodeado de pueblos guerreros y traficantes de esclavos, de los que ellos eran sus frecuentes víctimas.

\footnotetext{
${ }^{7}$ Hay varios trabajos importantes sobre el tema. Recomendamos los de Joanna Overing (1985, 1988, 1989a, 1989b y 1993), los de Jean Monod (1970, 1972 y 1987), los de Boglar (1976 y 1999) y los míos (MANSUTTI RODRÍGUEZ, 2003, 2006, 2007 y 2008).
} 
ALEXANDER MANSUTTI RODRÍGUEZ - Yuruparí: máscaras y poder entre los piaroas...

En contraste con la rigurosa prohibición a la violencia física, los piaroas son cultores del shamanismo de agresión. El shamanismo es el arte cultural por excelencia, pero el shamanismo y por ende la cultura no son monopolio de los seres humanos. En el mundo piaroa, las artes shamánicas están distribuidas entre muchos seres. Algunas sirven para destruir y otras para fecundar y crear. Ellas median las relaciones entre los hombres y entre éstos y todos los demás seres cultos al punto que la productividad del universo depende de la eficiencia de las relaciones entre los shamanes humanos y entre ellos y los shamanes no humanos.

\section{El Warime piaroa ${ }^{8}$}

El Warime es el evento ritual de mayor significación en el universo piaroa. Es reportado por primera vez para los piaroas a finales de la década de los 40's por Wavrin (1948) y Gheerbrant (1953). El ser Dueño de Warime es un atributo sustancial de la autoridad shamánica. Haber organizado varios de estos eventos es el más importante factor de prestigio de los viejos chamanes (BOGLAR, 1976; MANSUTTI RODRÍGUEZ, 1991). Para hacer un Warime es necesario que su convocante haya heredado el derecho y el instrumental para ejecutarlo. El ser Dueño de Warime es el equivalente a tener un rango de nobleza que puede ser heredado.

El Warime es una fiesta de la fertilidad y la fertilidad es un evento asociado a la eficacia shamánica en el mundo piaroa. Los piaroas lo definen como una batalla en la que el warimeruwa, dirige los esfuerzos de todos los miembros de su comunidad para garantizar la seguridad a un grupo selecto de aliados piaroas y de seres del cosmos que vienen a compartir con ellos y a los que debe defender de las agresiones de otros shamanes envidiosos, sean estos indígenas o no humanos (MANSUTTI RODRÍGUEZ, 2003 y 2008).

Todos los shamanes invitados son importantes. Los humanos son aliados en el esfuerzo permanente por contrarrestar las agresiones de

\footnotetext{
${ }^{8}$ Varias son las publicaciones, algunas de ellas recientes sobre el Warime. Recomendamos Agerkop (1983), Boglar (1976 y 1999), Monod (1972 y 1987), y los nuestros más recientes Mansutti Rodríguez (2006, 2011a y 2011b). Para una visión comparativa de flautas recomendamos Hill y Chaumeil (2011) y de las máscaras a Goulard (2011) y Karadimas (2011).
} 
los otros shamanes, tanto los humanos que los envidian y desean destruir la obra que hace feliz a la comunidad, como a los no humanos que controlan la fertilidad del mundo. Los otros shamanes humanos, por lo general piaroas también, se involucran en la fiesta. Incluso alguno de ellos trae consigo su propio Warime y lo expone en la fiesta. Los shamanes no humanos se expresan a los no iniciados como voces musicales, como animales o como Ojuodau en la forma de canoa de fermentación. Las voces musicales, a su vez, conforman una orquesta, generalmente nocturna, que nunca puede ser vista y sólo puede ser escuchada por las mujeres y los niños. Los animales enmascarados, Ojuodaa y Reyó por el contrario, realizan su escenografía frente a la vista de todos. Durante el día la fiesta privilegia el sentido de la vista; durante la noche el del oído (MANSUTTI RODRÍGUEZ, 2011 a y 2011 b).

\section{Personajes del Warime: las voces musicales}

Worá es la madre de todas las voces musicales del Warime. Está constituida por tres instrumentos: un par de tubos cilíndricos de corteza o de plástico PVC con un diámetro de embocadura relativamente ancho (una pulgada por ejemplo) y una olla de barro cocido que puede tener, sea como en el diseño de Gumilla (1988) (ver Figura 4), dos orificios laterales y opuestos, sea sin los orificios laterales como las registradas por nosotros (CHIAPPINO, 1993) y Agerkop (1983), en las que se introducen alternadamente las flautas simples ejecutadas cada una por un músico quien balancea su cabeza de manera que cuando él está ejecutando la suya dentro de la olla, su compañero tiene la suya fuera pero presto para introducirla cuando el otro esté sacando la propia. Dado el balanceo constante de los ejecutantes, uno de cada lado de la olla, se produce una alternancia de sonidos graves, profundos y rápidos que promueve un ambiente de excitación al interior de la maloca.

Luego está Chuvó, una flauta nasal, creada por Wajari, el demiurgo creador de los Piaroa durante los tiempos míticos quien la hace "hablar" sin que su hermana Chejeru la pueda ver. Su voz es tan hermosa que suscita en la hermana el deseo incestuoso de poseerla, 
provocando la aparición de las enfermedades y la muerte de sus hijos. Chuvó, por tanto, representa una voz cargada de eros, de deseo.

Figura 4: un instrumento similar a Wora, obtenida del misionero jesuita Joseph Gumilla

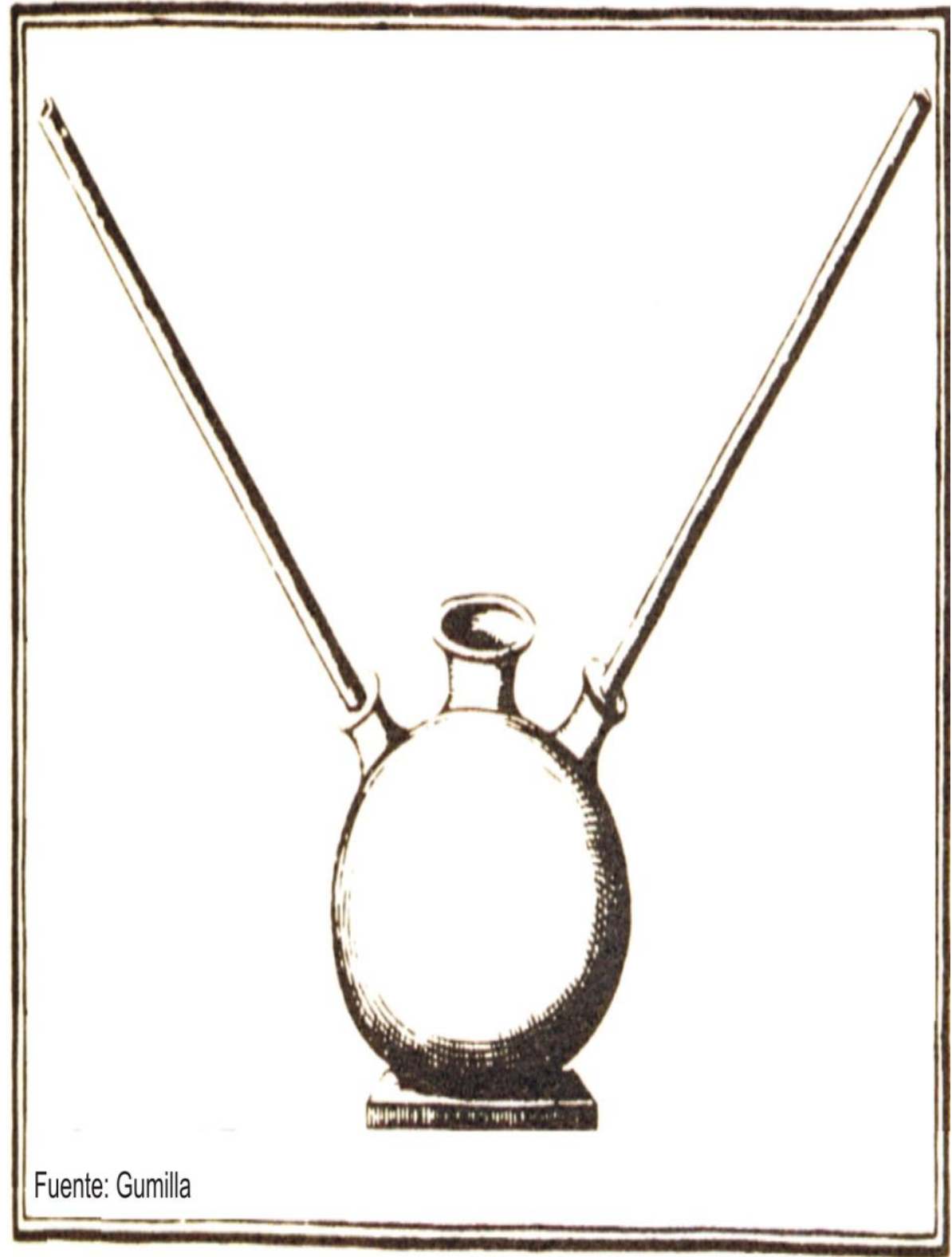

Chuvó es una flauta longitudinal, abierta, con un agujero de ejecución nasal. Para hacerla sonar se coloca el orificio que se encuentra en el medio de la embocadura de cera al extremo de la flauta, frente a 
uno de los orificios nasales del ejecutante por donde se expele con fuerza el aire de los pulmones de manera que la flauta, al recibirlo, emita su sonido. La flauta tiene un orificio en la sección opuesta a aquella donde se sopla modifica la altura tonal al ser tapado (Ver Figura $5)$.

Figura 5: Chuvó

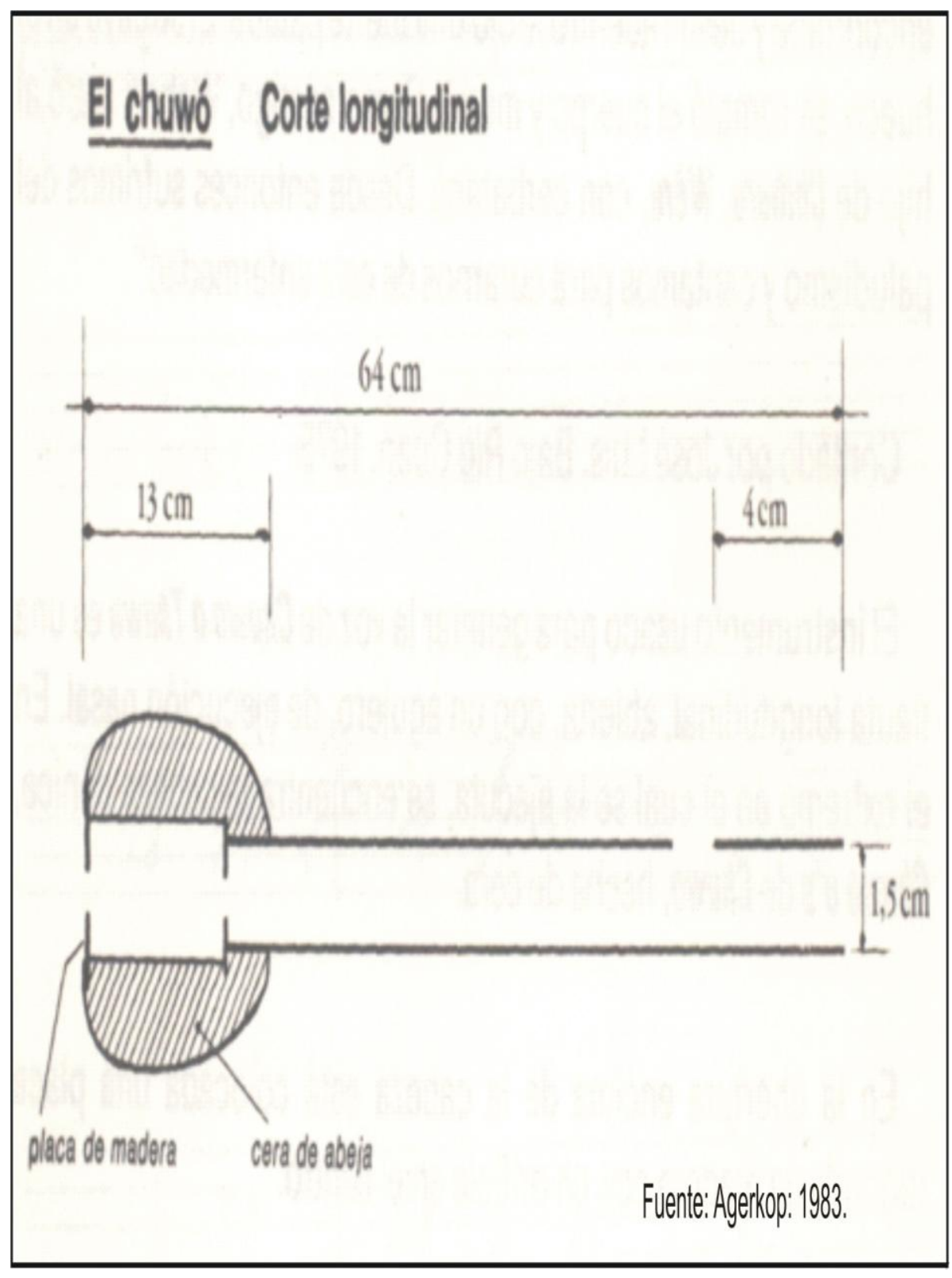

El tercer aerófono importante del Warime es Buoisa. Se trata de una lengüeta batiente constituida por una hoja de palma enmarcada 
entre dos piezas de madera de Maximiliana regia Mart. El ejecutante de Buoisa se coloca el instrumento entre los labios y con el aire expelido de su boca, hace vibrar la hoja entre el marco de madera. El sonido producido puede ser articulado de manera que Buoisa habla (Ver Figura 6).

Figura 6: Buoisa

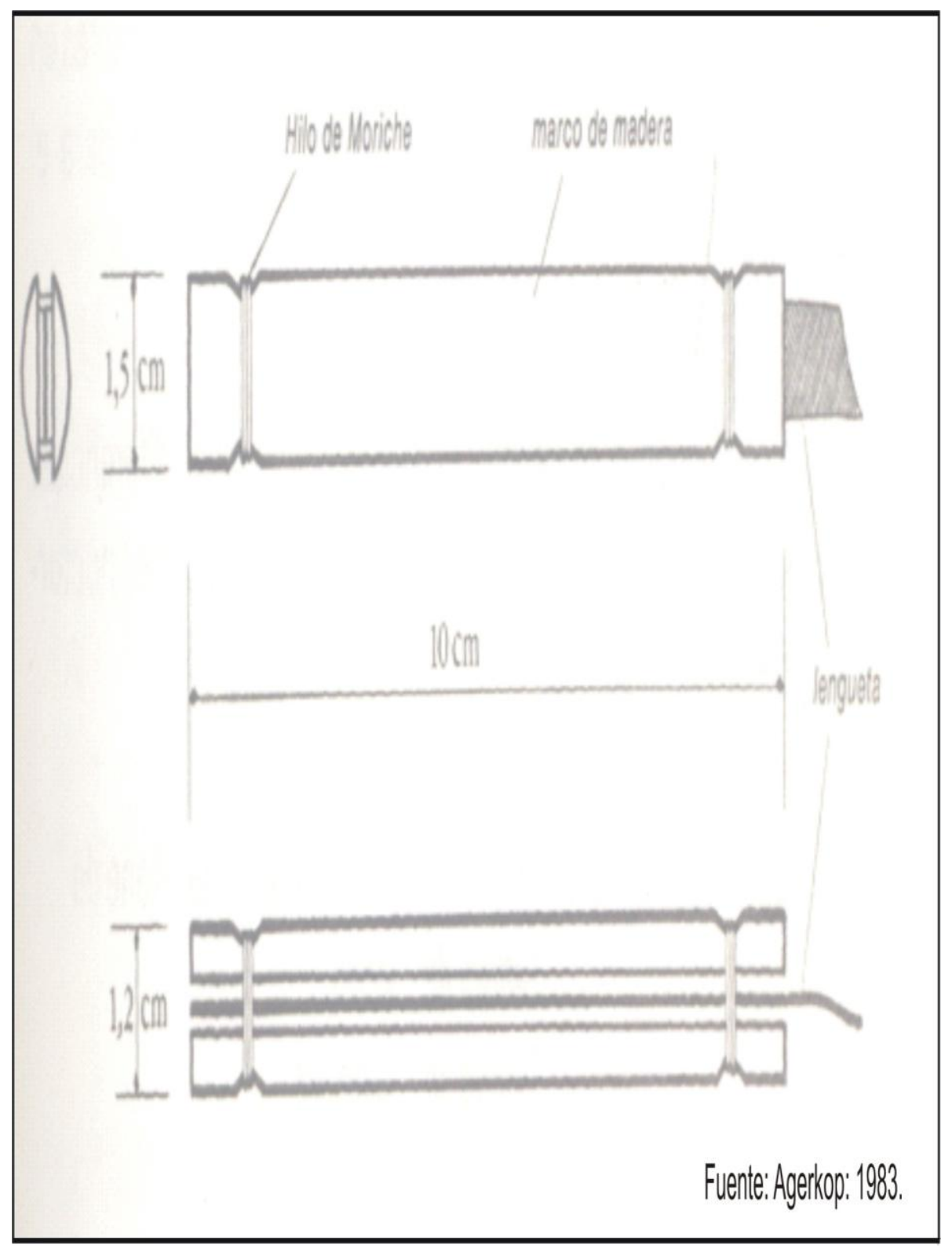

Wora, Chuvó y Buoisa son las tres voces más importantes del Warime. Luego aparecen el tucán Yajó, la anaconda Da'a, e Imu Chuvó 
el mono aullador (Alouatta seniculus). Yajó representa al tucán (Ramphastos aulacorhamphus) considerado uno de los dueños de las frutas, condición asociada a su insaciable apetito por ellas. Es una flauta sin orificios cuya musicalidad depende de la fuerza con la que se ejecute. Se usa para despertar al amanecer a los enmascarados de pécaris (Tayassu pécari o Tayassu tajacu) que han de visitar la maloca. Durante la noche, esta voz sale junto con las otras a emitir su voz musical. Da'a representa la voz de la anaconda (Eunectes murinus). Su voz resulta del manejo alternado de dos flautas, una masculina y otra femenina, con hoyos de diferente tamaño. Los dos ejecutantes van hombro con hombro haciendo sonar sus flautas. El último aerófono es Imú Chuvó, la voz del mono aullador (Alouatta senicoulos). Se trata de un resonador que se ensambla amarrando una cabuya de fibra de moriche (Mauritia flexuosa) por un orificio abierto en uno de los extremos de una lámina oblonga de madera dura y afilada en sus bordes, a la que, una vez amarrada, se le hace girar rápidamente usando la mano como eje para hacerla dar vueltas. Al hacer como las hélices de un avión genera un sonido muy parecido al aullido de los monos a los que representa.

Estos son los aerófonos registrados en nuestro yuruparí pero seguramente han de haberse usado otros ${ }^{9}$. De hecho se dice que hay muchas variedades de Warime y que ellos, aunque usan estos instrumentos básicos, también pueden usar otros instrumentos.

Esta es la orquesta básica de las flautas sagradas de un Warime convencional.

Sólo faltarían un idiófono pero que no es sagrado y está a la vista de todos: la maraca tejida (wiwito rediyu) que es usada sólo por los pécaris enmascarados que protagonizan el Warime. Es una maraca tejida con fibra de tirite (/chnosiphon spp.) que se llena con una fruta de cáscara dura que se llama wiwito (i). El sonido que genera es muy rápido y seco y sirve para marcar los tiempos de los cantos de los pécaris enmascarados. Su ejecución es vista por todos los espectadores del canto de los pécaris. No está, por tanto, sometida a restricciones severas como las flautas del Warime.

\footnotetext{
${ }^{9}$ En una foto de 1948, Gheerbrant (1953) registra unas trompas de grandes dimensiones, similares a las usadas en yuruparís arawakos, en manos de los piaroas que ejecutaron un Warime en su presencia.
} 
ALEXANDER MANSUTTI RODRÍGUEZ - Yuruparí: máscaras y poder entre los piaroas...

\section{Personajes del Warime: las máscaras piaroas}

Estos personajes son los que corresponderían a las fiestas de fecundidad de las frutas al sur y suroeste del Orinoco. La diferencia fundamental con las fiestas de los pijiguaos (Bactris gasipaes) es que en el Warime la identidad de los portadores de todas las máscaras es secreta y está terminantemente prohibido a las mujeres y a los no iniciados intentar ver quién se cubre detrás de las cortinas de fibras de Mauritia flexuosa que tapan las caras de los enmascarados. Hay máscaras que son reportadas en todas las fiestas que han sido registradas: la de los pécaris o Warimetsa, la de Reyó, la del mono Jichú y la del murciélago vampiro Kohue. Sin embargo, sabemos de la existencia de máscaras de arañas, de caimanes y de otros animales. Estimamos que lo canónico de la fiesta es la presencia de los pécaris y Reyó quienes representan respectivamente a los demiurgos creadores y al gran dueño de los animales y sus dueños. Mantenemos que el resto de las máscaras puede variar.

La figura principal es la de los warimetsa (Figura 7). El pécari principal del Imé Warime, aquel que se ubica en el medio y está flanqueado por los otros dos warimetsa, representa a Wajari, el demiurgo materializador del mundo piaroa quien regresa a la maloca de sus descendientes piaroa con forma de pécari principal para reiterar la canción que ofreció a su suegro caníbal en los tiempos primigenios. Lo mismo ocurre en el Wirö Warime donde la máscara principal también está en el medio pero de cinco, sólo que aquí se trata de un personaje indefinido, que no se identifica, y que bien pudiera ser el mismo Wajari, Buoka o algún otro. En el Ime Warime se cantará a los cerros del territorio tradicional piaroa. En el Wirö Warime se cantará a los cerros de la serranía del Sipapo, hogar ancestral de los wirö.

Aunque se llama igual, el enmascarado Reyó no es el Salvaje, enorme figura shamánica, incontrolada y no humana que rapta mujeres para procrear, tiene los pies volteados hacia atrás y es totalmente peluda. En realidad el enmascarado que asiste al Warime representa a Mará Reyó, con los mismos atributos físicos que Reyó pero poderoso 
espíritu, gran cazador y dueño de los animales de tierra y aire, quien controla el sistema de almacenes montañosos donde moran los espíritus que deben ser extraídos, fecundados y materializados por los meyeruwa. Es él el gran jefe de los dueños de los animales. Invitado al Warime, Mará Reyó aporta alimentos al llegar, danza sugestivamente y usa un garabato para tratar de capturar a las mujeres. Es tan libidinoso como su alter ego Reyó. Mará Reyó es el abuelo y dueño de los warimetsa o máscaras de pécaris.

Figura 7: los warimetsa en un Ime Warime

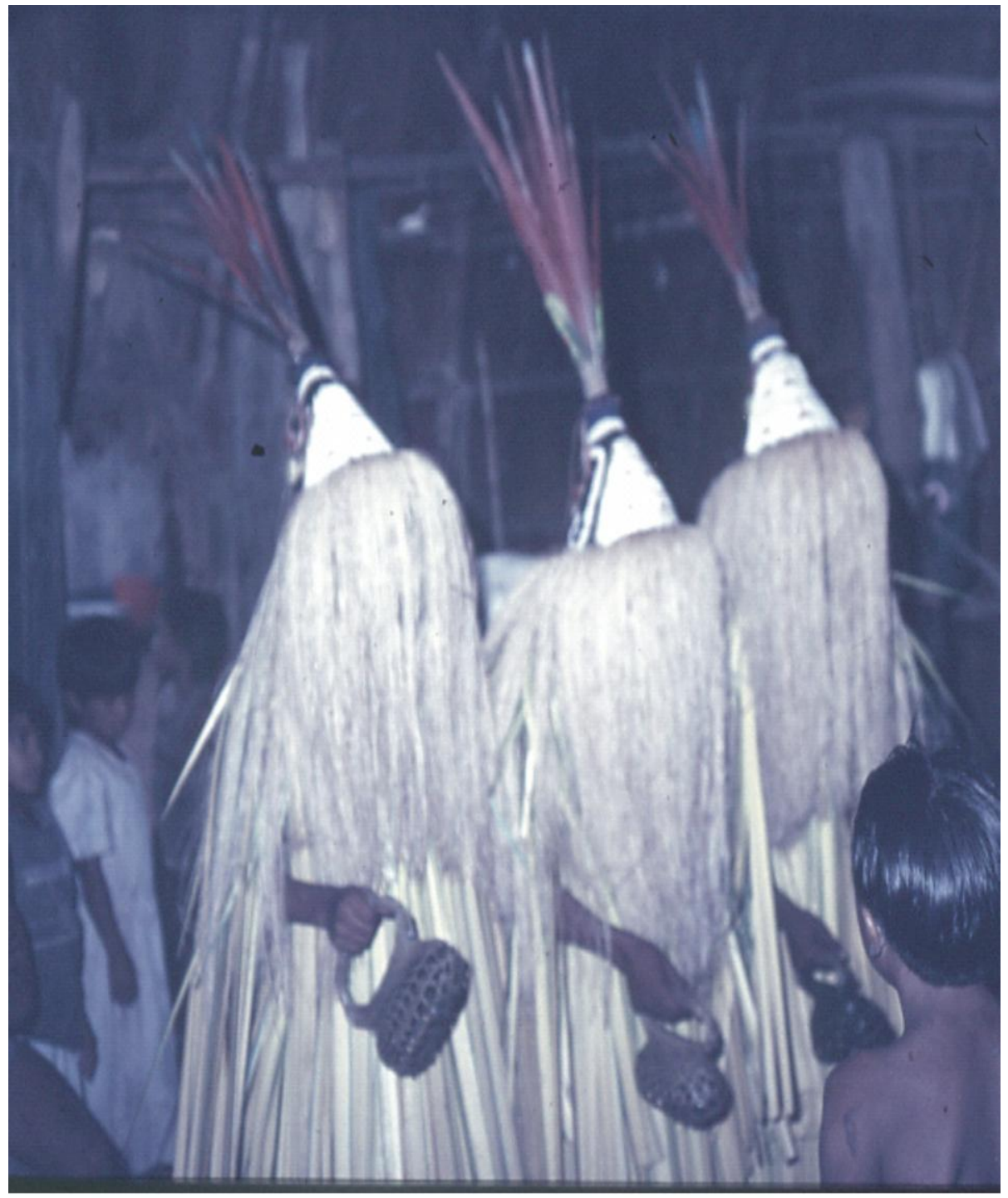

Fuente: Jean Chiappino. 
ALEXANDER MANSUTTI RODRÍGUEZ - Yuruparí: máscaras y poder entre los piaroas...

Viene también la máscara de Jichú, el mono blanco (Cebus olivaceus), incontrolable y jocoso, quien camina entre las hamacas para bromear con quienes en ellas se encuentran; y viene también Kuojuwa, el murciélago vampiro, arrastrado por el suelo, torpe y destructivo, quien apenas emite sonidos onomatopéyicos del animal que representa y pincha los pies de la gente de la misma manera que el murciélago vampiro lo haría para lamer la sangre que de la herida mana.

\section{Personajes del Warime: Ojuodaa}

Dentro de la maloca se encuentra representado Ojuodaa, el mítico ser espiritual dueño de las aguas y sus animales y por tanto dueño de la cerveza de yuca (Manihot sp.). Ojuodaa, palabra que viene de ojuo que significa tapir (Tapirus terrestris) y daa que significa anaconda (Eunectes murinus) es la metáfora del poder modelador y natural del mundo: el poder del rayo, de las aguas y del viento. Su vientre sirve de canoa de fermentación para la bebida fermentada de casabe que será ingerida por los comensales. No es una máscara y tampoco una voz musical. En ello se diferencia del resto de los actores.

Ojuodaa es el personaje de los tiempos primigenios que entrega a Wajari, el demiurgo que materializa el mundo piaroa soñado por Anamain, los poderes del shamanismo de agresión: La maripa. Es un ser que se mueve en las aguas y presta su cuerpo para hacer la canoa de fermentación cuando ocurre la fiesta de los peces. Aparece siempre como una figura generosa.

En el Warime, habrá tantos Ojuodaa como dueños de Warime estén mostrando su fiesta. Por lo general se ejecuta un solo Warime y por tanto hay un sólo Ojuodaa. Se trata del tallo de varios metros de largo de un árbol de madera blanda (por ejemplo Ceiba pentandra) al que se le talla una cabeza a cada extremo mientras a lo largo del fuste se le abre un orificio en el que se depositará y fermentará la cerveza de yuca, llamada sarí por los piaroas, que se consumirá durante la fiesta. El vientre de Ojuodaa sirve entonces de espacio para la fermentación de la bebida que habrá de ofrecerse a los participantes e invitados. Su figura es ubicada a lo largo de la zona central de la maloca, con una de sus 
cabezas justo en frente de la entrada. La cabeza que está frente a la entrada de la maloca será pintada de blanco, adornada con un collar de dientes de báquiro e ilustrada con la figura de animales comestibles como la araña, el armadillo y la culebra (ver figura 8). Ojuodaa es el dueño de los seres del agua.

Figura 8: cara frontal de Ojuodaa

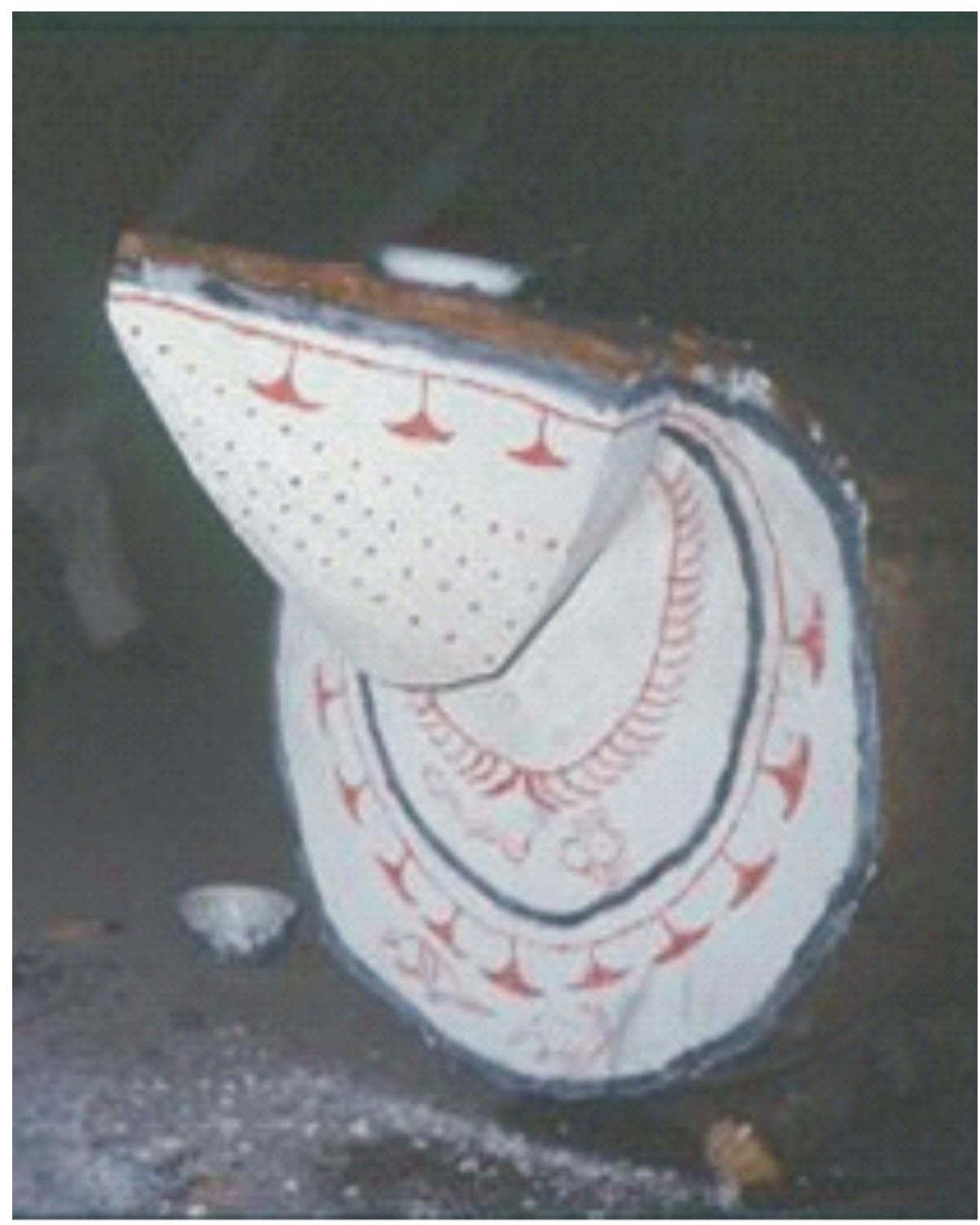

Fuente: Jean Chiappino.

El Warime: su escena 
La duración de un Warime varía entre un mes y varios meses en el ciclo de lluvias. Durante ese tiempo ocurren los siguientes eventos:

1. Se divide el espacio doméstico en un espacio hegemónicamente masculino representado en una "casa de los hombres" llamada ruwode que se construye a unos metros frente a la entrada de la maloca y otro dominantemente femenino, establecido al interior de la maloca comunitaria y que queda bajo el control de las mujeres.

2. Se invita a un conjunto de seres fantásticos conformado por Worá, Buoisa, Chuvó, Imú y Yajó que se manifestarán a los legos sólo por sus voces y que no podrán ser vistos por las mujeres ni por los niños no iniciados.

3. Se manufactura al menos una canoa de fermentación con la forma de Ojuodaa.

4. Se reproduce un evento mítico que adquiere la forma de un baile de máscaras en el que participan como mínimo pécaris (Tayassu pécari o Tayassu tajacu), un mono, un murciélago y un Marä Reyó.

5. Se ingieren y vomitan grandes cantidades de bebida fermentada con el fin de limpiar el cuerpo de sentimientos negativos.

6. Se celebra una serie de banquetes, se arreglan matrimonios y se consuman intercambios comerciales.

7. Se ejecutan rituales de transición y fortalecimiento.

Los preparativos de la fiesta comienzan al menos un mes antes de la llegada de los enmascarados, cuando el warimeruwa o "Dueño de Warime" decide construir la "La Casa del Dueño" o ruwode ${ }^{10}$. Al interior de esa pequeña casa de base circular se reúnen los hombres iniciados para manufacturar los instrumentos que están dañados y remozar aquellos que están en buen estado. Las mujeres y los niños deben conformarse con escuchar desde fuera el persistente canto de los pécaris -ju, ju, ju- (Tayassu sp) - y de la gran rana buréll pruu, pruu,

\footnotetext{
${ }^{10}$ Ruwode viene de ruwa, que significa "dueño" y "de" que es un sufijo que significa "maloca". La traducción literal es "maloca del dueño".

${ }^{11}$ Se trata de una rana Leptodactylus knudzeni que llega a pesar más de 300 gramos y que es considerado un manjar por los Piaroa. Justo en la entrada de las lluvias, cuando se decide la realización del Warime, ellas entran en celo y empiezan a cantar lo que facilita su captura y consumo. A diferencia de otros muchos animales, el consumo de buré no entraña peligro alguno, razón por la cual su carne no debe ser previamente rezada.
} 
pruu- (Leptodactylus knudzeni) que parecieran llenar su interior. Worá "habla" desde el ruwode cada vez que se inicia o culmina una fase importante de las tareas preparatorias del Warime, los pécaris y ranas lo hacen casi todo el tiempo sin guión establecido y siempre callándose o iniciando su letanía a una orden del Dueño de Warime. Finalmente, tenemos al araguato, imu chuvó, que se acompaña de un brusco remecido desde dentro del ruwode, con el fin de demostrar su presencia y disgusto a los curiosos que se acercan a observar lo que dentro de ella ocurre sin estar autorizados. El ruwode-dados los ruidos que salen de su interior- pareciera estar habitado por Worá e Imu Chuvó y lleno de pécaris y ranas que están preparando la fiesta.

\section{La fiesta se inicia}

Hasta la llegada de las máscaras, las voces musicales, especialmente Worá, son escuchadas desde dentro del ruwode o en los alrededores de donde se realiza una actividad importante como el talado del árbol cuyo fuste ha de servir para tallar la canoa de fermentación o allí donde se cortan los cogollos de la palmera Mauritia flexuosa que han de servir para elaborar la cortina de fibras que tapan las caras de los emmascarados. Sin embargo, no será sino poco antes del arribo de las máscaras, cuando todas las voces musicales invitadas llegan durante la noche al entorno exterior de la churuata y desde allí llenarán el ambiente con su música. Previamente, las mujeres han sido encerradas en la maloca. Este sonido orquestado con sus voces musicales y el enclaustramiento de las mujeres y los niños se va a repetir todas las noches, a veces más de una vez por noche.

El ambiente, cuando la orquesta de voces está sonando, es fantástico. Se combinan los sonidos alternados de Worá, con los ronquidos del araguato Imú Chuvó, las entonaciones suaves y melodiosas de Chuvó, los pitos de Yajó, los sonidos mellizales de Da'a y los chillidos agudos de los varios Buoisa que dan vueltas a la maloca. Todos juntos y simultáneos.

La víspera de la llegada de las máscaras los participantes del Warime y sus invitados ayunan y en la madrugada, antes del arribo de 
ALEXANDER MANSUTTI RODRÍGUEZ - Yuruparí: máscaras y poder entre los piaroas...

los enmascarados, se produce un vómito ritual que permite a los espectadores y protagonistas humanos de la fiesta deslastrarse de los malos sentimientos. Las máscaras salen del ruwode y se desplazan en fila con pasos cortitos, pegados uno a la espalda del otro, hasta llegar a la única entrada de la maloca. Luego de dar tres vueltas en sentido contrario a las agujas del reloj a la base circular de la maloca entran en ella, primero el Warime principal y luego los otros dos. Allí, justo después de la entrada y en un sitio donde les han dispuesto una estera para pararse sobre ella, entablan un diálogo con la mujer que es la esposa del Dueño de Warime, ella misma saríruwa o "Dueña de la Cerveza de Yuca" y anfitriona principal de los enmascarados. En este encuentro los warimetsa cantan el mismo discurso del demiurgo Wajari en el primer Warime de los tiempos originarios, mientras que las mujeres les responden entonando un texto autobiográfico que recuerda el sitio donde nacieron y se criaron y a sus familiares (ver figura 9). Entre canto y canto, los enmascarados reciben cerveza de yuca que beben levantando un poco la cortina de fibras vegetales que tapan sus caras pero evitando que otros los vean. En sus textos y gestos, el rito recrea los tiempos del mito por la voz de las máscaras e integra historia y mito en los tiempos contemporáneos por la voz autobiográfica de la mujer. El enmascarado representa la norma inmutable y la mujer la historia que inexorablemente cambia a los actores.

Con las máscaras se recrea varias veces al día un evento mítico ocurrido en el tiempo de las transmutaciones. Durante ese evento, Wajari el demiurgo, con la ayuda de su hermana Cheheru ofrece el primer Warime a su suegro caníbal bicéfalo Ilamado Kwemoi. En contraste, la noche es el tiempo de las voces sagradas, de los poderes actuales. Las máscaras desaparecen con el ocaso y en su relevo salen seres extraordinarios que van a circundar la maloca para emitir sus "palabras" musicales. Mientras mujeres, niños y algunos hombres están dentro de la maloca, fuera se escucha el concierto de voces.

De esta manera, reproduciendo durante el día las visitas de las máscaras y durante la noche la de las voces del mundo invisible, el Warime va desarrollándose día a día, unas veces promoviendo ritos de transición, otras sesiones curativas y otras intercambios comerciales y matrimoniales, todo en el marco de una comilona que expresa la 
abundancia y con ella, la capacidad del shamán para mantener prolífico su entorno.

Figura 9: diálogo ritual entre los warimetsa y la dueña del sari

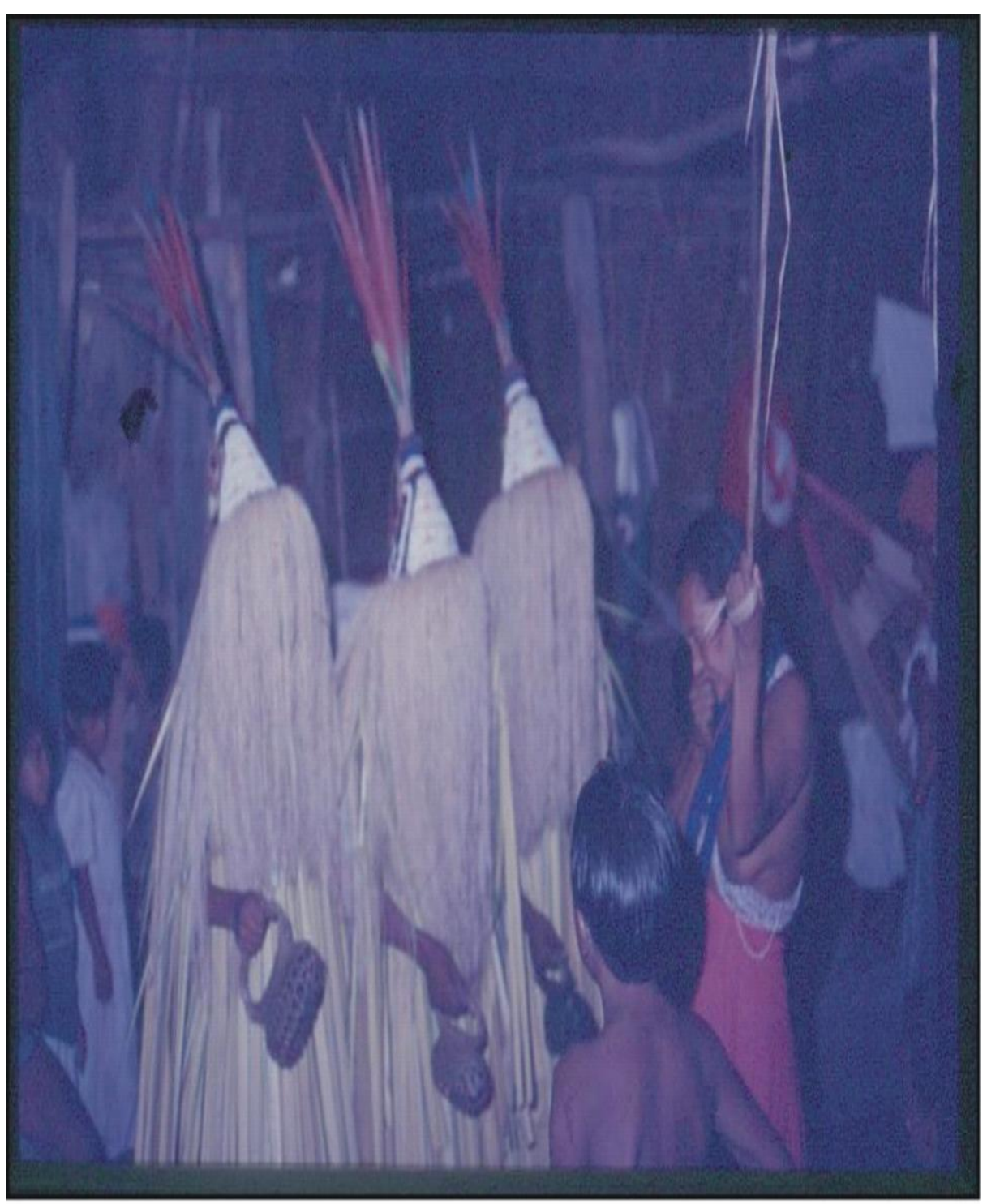

Fuente: Jean Chiappino.

\section{Libretos, voces y roles}

El Warime, cualquiera sea su modalidad, tiene un libreto que lo hace reconocible. Hay unos textos, una estructura, una sucesión, un protocolo y unos personajes que deben ser respetados. Lo más sacro 
del Warime es la cara de las voces musicales que crean desde fuera de la maloca el ambiente de diálogo ritual. Las máscaras y su escenografía, aunque también sagradas, se exponen más fácilmente tanto en la búsqueda y procesamiento de las materias primas con las que se elaboran como en la escenificación; ellas están a la vista de todos. Las voces musicales son las que se manufacturan en el más estricto secreto; son ellas las que ponen en juego poderes del mundo invisible no representados en las máscaras y otros instrumentos visibles: Esos poderes representan lo más avanzado del mundo de la cultura: la agricultura; poderes que regulan la vida y cuya presencia sólo puede ser escuchada y nunca vista por mujeres y niños no iniciados, so condena de muerte para toda la comunidad.

Las máscaras, nos hablan es de un mundo de predación, del mundo de la cacería y la pesca. Ellas son también sagradas. Ningún no iniciado puede pretender ver quienes se esconden tras el velo de fibras o tras la máscara que cubre sus rostros. Como en la visión de las flautas, la pena por tal osadía es la muerte para toda la comunidad. De hecho, el mito que relata este castigo narra que, una vez cometida la falta, todos los enmascarados se quitan sus máscaras durante el camino que ha de llevarlos a todos al sitio de la ejecución.

El Warime y sus personajes hacen parte de un sistema, de una coreografía que es consistente, por un lado, con un discurso de la vitalidad del mundo y los factores que lo ponen en peligro, y, por el otro, con una tradición cultural noroccidental amazónica que ha configurado una política de género montada sobre la diferenciación del acceso de los hombres y de las mujeres al instrumento societario que en las sociedades indígenas de tierras bajas en América del Sur permite concentrar poder: el shamanismo.

Esta diferenciación no sólo institucionaliza una expropiación, pues es bien sabido que muchas sociedades que practican ritos con flautas sagradas prohibidas a las mujeres tienen mitos que reconocen que en el inicio estos instrumentos eran de ellas (GOLDMAN, 1963; GONZALEZ ÑANEZ, 1986; HILL, 1993; WRIGHT, 1998; MANSUTTI RODRÍGUEZ, 2006), sino que produce una segmentación de espacios que consolida el poder femenino en el interior de la maloca y en la culinaria, mientras que concentra en los hombres el dominio shamánico. Haciendo esto 
ALEXANDER MANSUTTI RODRÍGUEZ - Yuruparí: máscaras y poder entre los piaroas...

divide radicalmente la percepción que hombres y mujeres tienen del mismo evento. Ocurre que mientras los hombres en el Warime representan un rito ocurrido en los tiempos del origen, las mujeres recrean este rito y lo encarnan como si estuviera ocurriendo de nuevo. Ellos lo actúan; ellas lo viven.

No es casual que en el Warime estén representados los personajes más característicos del mundo cultural piaroa: Worá representa a Worajuwa, la Dueña de los Productos de la Agricultura. Ojuodaa es el dueño del agua y con ella de los animales que allí habitan. Mará Reyó es el dueño de los animales de tierra y aire. Ojuodaa es el recipiente de la bebida de yuca fermentada; Mará Reyó llega enmascarado aportando frutas y cacería; Worá viene en forma de voz profunda, repetitiva y alternada pero prohibida. Una aproximación interpretativa surge: se le prohíbe a las mujeres la visión del poder del mundo agrícola, justamente aquel donde ellas son más poderosas cotidianamente, justamente aquel donde ellas fueron su origen mítico. Se les desplaza entonces del control shamánico de un espacio de poder, el espacio de la fertilidad donde ellas son fuertes, de un espacio cuyo control pudiera hacerlas autónomas frente a los hombres.

Si consideramos el protagonismo que ocupan en el rito y el poder que Mará Reyó, Ojuodaa y Woraju tienen sobre los recursos que necesitan los Piaroa para vivir, es fácil concluir que el Warime es un evento de renovación de las alianzas con los poderes a los que el shamán debe acudir regularmente para mantener surtido su territorio. El Warime puede considerarse entonces como un rito propiciador de la fertilidad y la riqueza. Esos personajes que allí asisten son los mismos a los que deberá invocar el rezador para que le permita entrar en los urou $^{12}$, fertilizar a los espíritus de los recursos, multiplicarlos y materializarlos (MANSUTTI RODRÍGUEZ, 1997).

\footnotetext{
${ }^{12}$ La palabra urou significa "cueva". En el lenguaje shamánico significa depósito de los espíritus de animales y vegetales que viven en la selva y que están guardados en el corazón de las montanas bajo la custodia de un Dueño de esa clase de animales que se caracteriza por su estatura y vejez. Este dueño está sometido al control de Mara Reyo quien es el jefe de todos ellos. Dicen los meyeruwa piaroa que en el urou principal de Mara Reyó, éste tiene una suerte de galería sumida en la neblina donde cuelga las fotos de todos los dueños de los animales que están bajo su control. Cuando el shamán quiere surtir su zona de vida, le reza a Mara Reyo, a los dueños de los animales y pide autorización para sacar de los urou espíritus de animales y vegetales con los que quiere surtir su territorio, los insemina con el poder de su palabra, los multiplica, los materializa y los suelta en el territorio bajo su resguardo.
}

Espaço Ameríndio, Porto Alegre, v. 6, n. 2, p. 46-75, jul./dez. 2012. 
ALEXANDER MANSUTTI RODRÍGUEZ - Yuruparí: máscaras y poder entre los piaroas...

\section{Conclusión}

La fiesta de máscaras y flautas piaroa es claramente una modalidad de yuruparí pues expresa una política de género asociada a instrumentos sagrados prohibidos a la mirada de las mujeres quienes fueron expropiadas de ellos, incluye la pena de muerte para los transgresores, el consumo de copiosas cantidades de alimentos, espacios masculinos solo accesibles a los iniciados, espacios femeninos a los que si pueden acceder los hombres y ritos de pasaje y fortalecimiento. Tiene una diferencia fundamental con otros yuruparís: el Warime es un ritual complejo egocentrado, es decir guayanizado. A diferencia de otros yuruparí en los que grupos de descendencia comparten atributos de la fiesta que obligan al trabajo colectivo, en el Warime es la decisión de una pareja, hombre y mujer, la que decide si se hace o no la fiesta, la mujer para controlar la producción de alimentos y bebidas que se van a ofrecer y el hombre para garantizar que asistan los seres cósmicos que hacen posible la vida.

El efecto más interesante que tiene el Warime sobre la estructura de poder piaroa es su capacidad de generar en lo cotidiano una estructura de jerarquía vertical, piramidal y rígida, que atraviesa grupos etarios y de género, en una sociedad donde lo que existe es una estructura horizontalizada de poderes en la que hombres y mujeres participan en las decisiones cotidianas, en la que los shamanes sugieren y orientan pero pocas veces ordenan, en la que las correlaciones de fuerza son volátiles y las relaciones de subordinación, cuando existen, tienen límites que no pueden ser sobrepasados. Como en el caso de los Katchim de la Alta Birmania estudiados por Leach (1976) una sociedad a poder descentralizado súbitamente se convierte en una sociedad a poder central durante una parte del año, en nuestro caso gracias a un atractor: una fiesta llena de arbitrarios que regula el acceso al poder de hombres y mujeres, adultos y niños. 
ALEXANDER MANSUTTI RODRÍGUEZ - Yuruparí: máscaras y poder entre los piaroas...

\section{Bibliografía}

AGERKOP, Terry Piaroa. Venezuela. Caracas: INIDEF, 1983.

ANDUZE, Pablo. Dearuwa: los dueños de la selva. Biblioteca de la Academia de Ciencias Físicas, Matemáticas y Naturales, vol. XVIII. Caracas: Talleres Topográficos de la Dirección de Cartografía Nacional, 1974.

ARHEM, Kaj. Makuna social organisation: a study in descent, alliance and the formation of corporate groups in the North-Western Amazon. Uppsala: Acta Universitatis Upsaliensis, 1981.

Makuna: a portrait of an amazonian people. Washington/Londres: Smithsonian Institution Press, 1998.

BOGLAR, Lajos. Creative Process in Ritual Art: Venezuela. In: The Realm of the Extra Human. La Hague: Mouton Publishers, 1976. p. 347-353.

Warime: el poder de las máscaras. In: DELMONT, Juan Luis (Org.). Orinoco, Parima: Comunidades indígenas de Venezuela. Alemania: Ostfildern Ruit, 1999. p. 162-187.

CHAUMEIL, Jean Pierre. Voir, savoir, pouvoir. Paris: EHESS, 1983.

Speaking tubes: the sonorous language of yagua flutes. In: HILL, Jonathan; CHAUMEIL, Jean Pierre (Orgs). Burst of breath: indigenous ritual wind instruments in Lowland South America. Lincoln: University of Nebraska Press, 2011. p 49-68.

CHIAPPINO, Jean. Warime 89: fête des masques dans une communauté Wotjuja, document audio-visuel. Paris : IRD, 1993.

GHEERBRANT, Alain. L'Expedition Orénoque-Amazone. Paris: Gallimard, 1953.

GOLDMAN, Irving. Tribes of the Vaupés-Caquetá región. In: Julian Steward (Org). Handbook of South American Indians. Vol III. Washington: Smithsonian Institute, 1948. p. 763-798.

The Cubeo: Indians of the Northwest Amazon. Chicago, Londres y La Urbana: University of Illinois Press, 1963.

GONZALEZ NANEZ, Omar. Sexualidad y rituales de iniciación entre los indígenas warekena del río Guainía-Río Negro. TFA, Montalbán, v. 17, p. 103-108, 1986.

GOULARD, Jean Pierre. La surface du masque: perpetuation et métamorphose chez les Tikuna. In: GOULARD, Jean Pierre; KARADIMAS Dimitri. (Orgs.). Masque des hommes visages des dieux. Paris: CNRS Editions. 2011. p. 129-154. 
ALEXANDER MANSUTTI RODRÍGUEZ - Yuruparí: máscaras y poder entre los piaroas...

GUMILLA, Joseph (sj). El Orinoco ilustrado y defendido, historia natural, civil, geographica de este gran río, y de sus caudalosas vertientes. Gobierno, usos, y costumbres de los indios fus habitadores, con nuevas y utiles noticias de Animales, Arboles, Frutos, Aceytes, Refinas, Yervas, y Raices medicinales y fobretodo fe hallaran converfiones muy fingulares a N. Santa Fé, y cafos de mucha edificación. Valencia: Generalitat Valenciana, 1988.

HILL, Jonathan. Representaciones musicales como estructuras adaptativas: la musica de los bailes ceremoniales de los Arawakos Wakuenai. Montalblan, v. 17, p. 67-101, 1986.

Keepers of the sacred chants: the poetics of ritual power in an Amazonian society. Tucson: University of Arizona Press. 1993.

Ethnogenesis in the Northwest Amazon: an emerging regional picture. In: (Org.). History, power and identity. Iowa city: University of Iowa Press, 1996. p. $142-160$.

Shamanism, colonialism, and the wild woman: Fertility cultism and historical dynamics in the Upper Rio Negro region. In: HILL, Jonathan; SANTOS GRANERO, Fernando (Orgs). Comparative arawakan history: rethinking language family and culture area in Amazonia. Chicago y La Urbana: University of Illinois Press, 2002. p. 223-247.

Soundscaping the world: the cultural poetics of power and meaning in wakuenai flute music. In: HILL, Jonathan; CHAUMEIL, Jean Pierre (Orgs). Burst of breath: indigenous ritual wind instruments in Lowland South America. Lincoln: University of Nebraska Press. 2011. p. 93-122.

HILL, Jonathan; CHAUMEIL, Jean Pierre (Orgs). Burst of breath: Indigenous ritual wind instruments in Lowland South America. Lincoln: University of Nebraska Press. 2011.

HUGH JONES, Christine. From the milk river. Cambridge: Cambridge University Press. 1979.

HUGH JONES, Stephen. The palm and the pleiades. Cambridge: Cambridge University Press. 1979.

Clear descent or ambiguous houses? A reexamination of tukanoan social organisation. L'Homme, Paris, n. 126-128, p. 95-120, 1993.

Inside out and back to front: The androgynous house in northwest Amazonie. In: About the house. Cambridge: Cambridge University Press, 1995 .p. 227-252.

JACKSON, Jean. The fish people: linguistic exogamy and tukanoan identity in northwest Amazonia. Cambridge: Cambridge University Press. 1983. 
ALEXANDER MANSUTTI RODRÍGUEZ - Yuruparí: máscaras y poder entre los piaroas...

JOURNET, Nicolás. Hearings without seeing: sound flutes as the medium for an avowed secret in curripaco masculine ritual. In: HILL, Jonathan; CHAUMEIL, Jean Pierre (Orgs). Burst of breath: Indigenous ritual wind instruments in lowland South America. Lincoln: University of Nebraska Press. 2011. p. 123-146.

KARADIMAS, Dimitri. La masque et la raie: étude ethno-asthronomique de l'iconographie d'une masque Miraña. L'Homme, Paris, n. 165, p. 173-204, 2003.

Depuis l'interior du masque: Construction du sujet et perception de l'Autre chez les Miraña d'Amazonie colombienne. In: GOULARD, Jean Pierre; KARADIMAS, Dimitri (Orgs). Masques des hommes, visages desd dieux. Paris: CNRS Editions. 2011. p. 205-228.

LEACH, Edmund Raymond. Sistemas políticos de la Alta Birmania: estudio sobre la estructura social Kachin. Barcelona: Editorial Anagrama, 1976.

LOWIE, Robert. The Tropical forests: an Introduction. In: STEWARD, Julian (Org.). Handbook of South American indians. Washington: Smithsonian Institute, 1948. p. 156.

MANSUTTI RODRIGUEZ, Alexander. Los Piaroa y su territorio. Monografía $\mathrm{N}^{\circ} 8$, Ceviap: Caracas. 1990.

MANSUTTI RODRIGUEZ, Alexander. Sans guerriers il n'y a pas de guerre. Memoria de DEA en Antropología Social y Etnología, EHESS, Paris. 1991

MANSUTTI RODRIGUEZ, Alexander. Meñeruwas y empresarios: ambiente y desarrollo en tierras Piaroas. En: R. J. Carrillo (Org). Memorias del IV Congreso Interamericano sobre el Medio Ambiente, realizado en Caracas, Venezuela, entre el 8 y 11 de diciembre de 1997. Colección Simposia, Volumen II: 334 Pág. Caracas: Editorial Equinoccio, Ediciones de la Universidad Simón Bolívar. P. 199-204. 1997.

MANSUTTI RODRIGUEZ, Alexander. Piaroa: los guerreros del mundo invisible. Antropológica, n. 99-100, p. 97-116. 2003

Warime: La fiesta, flautas, poder y sociedad en el noroeste amazónico. Ciudad Guayana: Fondo Editorial UNEG, 2006.

Rituales, demografía y violencia: el sistema de interdependencia regional del Orinoco visto desde algunos de sus atributos. In: MENESES PACHECO, Lino; GORDONES, Gladis; CLARAC DE BRICENO, Jacqueline (Orgs.). Lecturas antropológicas de Venezuela. Mérida: ULA-Editorial Venezolana, 2007. p. 247-255.

Envy and revenge: the case of the piaroa. In: BECKERMAN, Stephen; VALENTINE, Paul (Orgs.). Revenge in the Cultures of Lowland South America. Gainsville: University Press of Florida, 2008. p. 216-232. 
ALEXANDER MANSUTTI RODRÍGUEZ - Yuruparí: máscaras y poder entre los piaroas...

Les masques des pouvoirs: le warime piaroa. In: GOULARD, Jean Pierre; KARADIMAS, Dimitri (Orgs). Masques des hommes, visages desd dieux. Paris: CNRS Editions, 2011a. p. 155-181.

Flutes in the Warime: musical voices in the Piaroa world. In: HILL, Jonathan; CHAUMEIL, Jean Pierre (Orgs). Burst of breath: indigenous ritual wind instruments in lowland South America. Lincoln: University of Nebraska Press, 2011b. p. 147-170.

El largo camino de las criaturas de Wajari: piaroas, sistemas de interdependencia regional y poblamiento en el Orinoco Medio. Trabajo de Ascenso para optar a la categoría de Profesor Titular. Ciudad Bolívar: UNEG, 2011c.

METRAUX, Alfred. Les Indiens de l'Amérique du Sud. Paris: Editions A.M. Metailié, 1982.

MONOD, Jean. Los Piaroa y lo invisible: ejercicio preliminar de un estudio sobre la religion Piaroa. Boletin Informativo de Antropologia, v. 7, p. 5-21, 1970.

Un riche cannibale. Paris: Union Générale d'Editions, 1972.

Wora: la deesse cachée. Paris; Les Editeurs Evidant, 1987.

OVERING, Joanna. The Piaroa: a people of the Orinoco Basin - a study on kinship and marriage. Oxford: Clarendon Press. 1975.

There is no end of evil: the guilty innocents and their fallible god. In: PARKIN, David (Org) . The anthropology of evil. Oxford: Basil Blackwell, 1985. p. 244-288.

Personal autonomy and the domestication of the self in Piaroa Society. In: JAHODA, Gustav y Lewis (Org.). Acquiring culture: Cross cultural studies in child development. London and New Cork: Croom Helm, 1988. p. 169-192.

The aesthetics of production: The sense of community among the Cubeo and Piaroa. Dialectical Anthropology, n. 14, p. 159-175, 1989a.

Styles of manhood: an amazonian contrast in tranquility and violence. In: HOWELL, Signe; WILLYS, Roy (Orgs). Societies at peace. London and New Cork: Routledge. 1989b. p. 79-99.

Death and the loss of civilized predation among the piaroa of the Orinoco basin. L'Homme, Paris, v. 126-128, p.191-211, 1993.

OVERING, Joanna; KAPLAN, M. R. Los Wothuha (Piaroa). In: COPPENS, Walter (Org). Los Aborígenes de Venezuela, vol. III. Caracas: Monte Avila, Fundación La Salle de Ciencias Naturales, 1988. p. 307-411. 
ALEXANDER MANSUTTI RODRÍGUEZ - Yuruparí: máscaras y poder entre los piaroas...

OYUELA CAICEDO, Augusto. The ecology of a masked dance: negotiating at the frontier of identity in the Northwest Amazon. Baessler-Archiv, Beitrage zur volkerkunde, Band, v. 52, p. 52-74, 2004.

PEREZ BETANCOURT, Sergio. Rito y manufactura entre los indios Piaroa. Caracas: UCV, 1986.

REICHEL DOLMATOFF, Gerardo. Desana: le symbolisme universal des indiens Tukano du Vaupés. Paris: Gallimard, 1973.

Yuruparí: studies of an Amazonian foundation myth. Cambridge: Cambridge University Press, 1996.

El chamán y el jaguar. México: Siglo XXI Editores, 1978.

VIDAL, Silvia. Kuwe Duwakalumi: the arawak sacred routes of migration, trade and resistance. Ethnohistory, v. 47, n. 3-4, p. 635-668, 2000.

Secret religious cults and political leadership: Multiethnic confederacies from Northwestern Amazonie. In: HILL, Jonathan; SANTOS GRANERO, Fernando (Orgs). Comparative arawakan history: rethinking language family and cultura area in Amazonia. Chicago y La Urbana: University of Illinois Press, 2002. p. 248-268.

WAVRIN, Marquis de. Les indiens sauvages de l'Amérique du Sud: vie sociale. Paris: Payot, 1948.

WILBERT, Johannes. Indios de la región Orinoco-Ventuari. Caracas: Fundación La Salle de Ciencias Naturales, 1966.

WRIGHT, Robin. Cosmos, self, and history in Baniwa Religion: for those unborn. Austin: University of Texas Press, 1998.

Prophetic traditions among tehe baniwa and other arawakan peoples of the Northwest Amazon. In: HILL, Jonathan; SANTOS GRANERO, Fernando (Orgs). Comparative arawakan history: rethinking language family and cultura area in Amazonia. Chicago y La Urbana: University of Illinois Press, 2002. p. 269-293. 